\title{
The nomads of the sky
}

Edward Harrison

Comets: A Chronological History of Observation, Science, Myth and Folklore. By Donald K. Yeomans. Wiley: 1991. Pp.485. £24.95, \$38.95.

Like the red star that from his flaming hair

Shakes down diseases, pestilence, and war.

(Homer, Iliad.)

COMETs have fascinated the curious and terrified the superstitious since antiquity. In his authoritative Comets: A Chronological History of Observation, Science, Myth and Folklore, Donald Yeomans tells a gripping story in the history of science - of the comings and goings of comets, interwoven with biographical detail of the astronomers and mathematicians who have observed and studied them - that culminates in the rendezvous mission of the Halley spacecraft armada of 1986.

The opening chapters recount the popular and scholarly beliefs about comets through the ages. In observations and explanations, the Chinese were ahead of the Arabs and Europeans until the high Middle Ages. With the rise of the cartesian and newtonian systems, comets became a major astronomical problem: were they members of the Solar System or visitors from distant star worlds? Almost every astronomer performs a part in the colourful parade. Naturally, not everybody gets mentioned; a conspicuous omission by Yeomans is Otto von Guericke, Mayor of Magdeburg, celebrated for his sensational experiments with large evacuated vessels, who in 1650 argued that comets are periodic. In the appendix, Yeomans catalogues comets seen by naked eye in recorded history to $\mathrm{AD} 1700$, in which Comet Halley can be traced back to the Chinese 'broom star' of $240 \mathrm{BC}$.

Until recent times, comets were feared as omens foreshadowing plague, famine and war. Disasters of one kind or another are forever with us and the credibility of the omens was rarely in doubt. Unintentionally, Edmund Halley added to the ancient fears a new fear of cometary impacts when he suggested in 1694 that an Earth-comet encounter had caused the biblical deluge. Prophets claiming that each bright comet foretells the end of the world have never been in short supply.

The immutable crystalline spheres of Aristotle and Ptolemy condemned all transient celestial phenomena as imperfect and sublunar. Comets in the Judaic-ChristianIslamic world of the Middle Ages were terrestrial exhalations, material enough to explain their transience, ethereal enough to serve as vehicles of heavenly wrath. But science was on the rise, and observations began to indicate that comets exist above the lunar sphere. The realization in the sixteenth century that the crystal spheres would be shattered by the passage of comets contributed to the downfall of the ptolemaic system and the success of the copernican revolution. But fear of cometary apparitions cannot be blamed entirely on our aristotelian heritage; Homer regarded them as malefic agents, and cometary entries in the silk book of the Chinese, dating

mundanities of human life. Astronomers justly condemn modern astrology, but go too far when they decry the astrology of the past; have they forgotten that out of the astral forces of the mediaeval universe arose the newtonian theory of universal gravity - a theory long rejected by continental scientists because of its astrological origins?

Yeomans makes an interesting point; he notices that Aristotle and Seneca relate their own views on comets after they have discussed and rejected those of their predecessors, "thus taking the remarkably modern stance of mentioning their sources only when they disagreed with them." This sweeping comment came to me as a shock; to what extent do modern scientists cover up their seminal sources, and give prominence only to references that are incidental and vulnerable to disproof? Is this one more feature on the dark side of science? We all travel on rutted roads of thought without paying tribute, but how many, when on little-trodden trails, conceal that they follow blaze marks made by others?

In the last chapters, Yeomans covers a wide diversity of cometary phenomena and emphasizes that we still do not know how comets originate. According to modern tentative ideas, the nucleus of a comet consists of a conglomeration of ice and dust and is only a few kilometres in size. When the comet approaches the Sun, the nucleus is surrounded by an extended atmosphere of gas and sub-micrometre grains of dust. Comet tails divide into two general groups: dust tails propelled by the pressure of sunlight, and gas tails entangled in the solar wind. A vast swarm (the Oort cloud) or approximately a trillion $\left(10^{12}\right)$ comets back to the fourth century $\mathrm{BC}$, relate to significant events, usually disasters, such as rebellion and famine.

Yeomans condemns as astrological many of the celestial beliefs of the past. Most astronomers from Babylonian times to the late Middle Ages were astrologers. But astronomers generally fail to realize that astrology had not quite its present meaning. Astrology was the science of planets and stars, of celestial influences, dealing with the physical and etheric interactions between celestial bodies and the Earth. Eclipses and comets in the heavens and tides and seasons on Earth were associated with the play of astral forces. Side by side with astrology, particularly in the Roman Empire, flourished the temple arts of astrolatry (worship of astral bodies) and astromancy (astral divination and soothsaying). Since the seventeenth century, astrology has been superseded by astronomy, and all that is left to astrology is astromancy, concerned with the influence of planets on the 
the past and the present greatly adds to the entertainment. But what of the reader unversed in astronomy? An editor once told me that she had no patience with the history of science; trying to understand modern ideas was difficult enough, why get confused and "misled by the false ideas of the past?" Authors of history-of-science books try to avoid confusing readers who are not scientists by retailing only ideas that modern science deems correct, and recounting only the lives of scientists that modern science deems important. These authors commit the whig sin of conforming the past to the present. Yeomans, to his credit, in a masterly work, tries to solve the problem; his first eight chapters deal with the history of comets, including the 'false ideas', and the last three chapters outline recent developments. But the going gets tough, and I still wonder, is it not true that the history of science, as a learned discipline, is for scientists only?

Edward Harrison is in the Department of Physics and Astronomy, University of Massachusetts, Amherst, Massachusetts 01002, USA.

\section{Cathedrals of science}

\section{Martin Ward}

The Creation of the Anglo-Australian Observatory. By S.C.B. Gascoigne, K. M. Proust and M. O. Robins. Cambridge University Press: 1990. Pp.301. £40, $\$ 59.50$

THE construction of a large modern telescope has been likened to the building of a mediaeval cathedral, in terms of the use of state-of-the-art contemporary technology and the aesthetic quality of the finished product. This point can be forcefully appreciated if one stands on the observing floor of the Anglo-Australian Telescope (AAT) and gazes up into the cavernous expanse inside the dome. The Creation of the AngloAustralian Observatory by S. Gascoigne, K. Proust and M. Robins traces the history of the AAT from the early days of identifying the need for such a facility, through project management, technical design considerations, commissioning, and finally lists a selection of its major contributions to astronomy. Although the building of the AAT took considerably less time than the construction of a gothic cathedral, and was not interrupted by the black death, some equally traumatic problems had to be overcome.

The AAT is a major chronological landmark in the development of UK observational astronomy during this century. The book relates how it caused a fundamental change in attitude and observing practice from the previous style of pottering about with small telescopes located within Britain, at sites which are extremely poor by interna- tional standards. A gentlemanly pursuit perhaps, but not one which resulted in Britain contributing greatly to the list of fundamental observational discoveries during the first part of this century. As our first major astronomical optical national facility, the AAT catapulted Britain into the big league. As a consequence, instead of joining the brain drain of the 1960s and 1970s, young British astronomers were able to look their Californian counterparts eye-to-eye without feeling like poor relations.

Much of the book deals with the mechanics of setting up the project, negotiating for funding from the respective British and Australian grant awarding bodies, and at a higher level, the political implications of a largescale bilateral project. Although the book does go into some technical aspects of the design, both optical/mechanical and computational, its main purpose seems to be to record the organizational and personal struggles, and how by cajolery and compromise somehow the project was brought through to a successful conclusion. In consequence, the book will probably hold particular interest for persons involved in project management and organizational structure, rather than to those wishing to learn some astronomy. Indeed, it makes no claim to be a textbook.

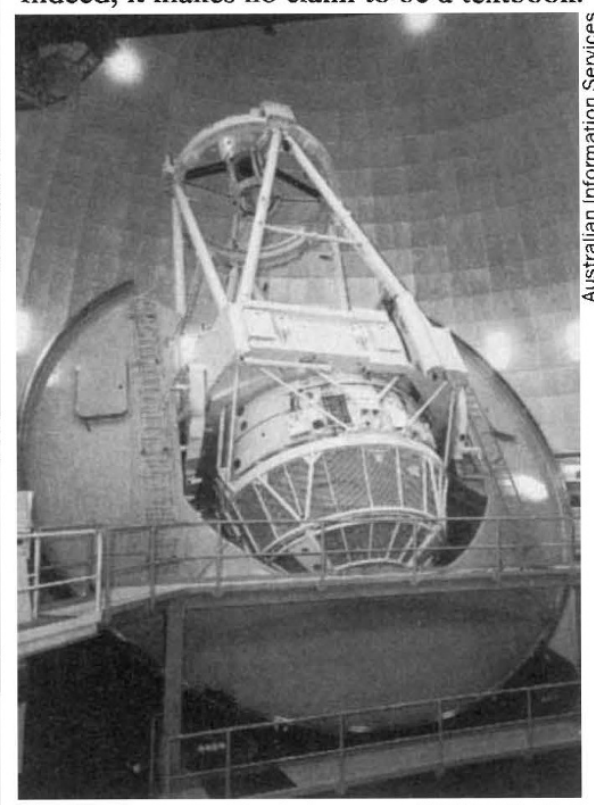

The Anglo-Australian telescope, Siding Spring Observatory, Coonabarabran.

Some nice touches found in this book are the incidents of human interest, such as a senior member of the Australian National University (ANU) staff reputably seen during the opening ceremony raising the university flag above that of the royal standard, in flagrant violation of protocol. Another is that we are given the opportunity to read the text of speeches by a prime minister and a royal personage, leading to interesting conclusions concerning their respective speech writers.

The authors draw some morals from their story. For example, as a first-class large telescope with state-of-the-art instrumentation and a dedicated staff, the AAT produces scientific data of the very highest quality. These factors to a large extent overcome the disadvantage that the site chosen for the AAT, although probably the best available in Australia, is only in the seocnd rank by global standards. Another conclusion is that the definition of the controlling body for the telescope should have been better defined at an early stage. This would have avoided a long running and often acrimonious dispute between the ANU and the AAT Board over who had the responsibility of running the telescope. This dispute blighted early attempts to appoint a director, and on occasion even looked like wrecking the project. Another important lesson concerns the basic design of the telescope. If a good design is available from another source, in this case the US project to build large telscopes in Chile and Arizona, there is little to be gained from re-inventing the wheel. Better to modify a sound design in the light of lessons learned or specific requirements, than to start from scratch. The latter approach would have been a recipe for extra expense and delay. The AAT was completed so quickly largely because it followed an existing design.

The book comments on some other features that contributed to the success of the AAT. For the first time at this level of sophistication, computers were closely interfaced with the operation of the telescope. This simple yet brilliant innovation resulted in the acquisition of astronomical objects, that is, the pointing of the telescope, with unprecedented accuracy. This gave the AAT its legendary reputation as a user-friendly telescope, a situation particularly valued by visiting astronomers. Finally, the symbiosis of the AAT and the nearby Schmidt Telescope used for wide-field survey work, is striking. Since 1988 the AAT and the Schmidt have been administratively combined to form the two-telescope Anglo-Australian Observatory. The book relates the curious tale of how the Schmidt Telescope was only funded originally because it fitted into a Science Research Council spend profile, thereby pushing radio astronomers aside, despite their having what was perceived at the time as a more desirable project.

The story of the AAT is certainly worth setting down, and a place should be found for The Creation of the Anglo-Australian $\mathrm{Ob}$ servatory in sections of libraries dealing with the history of science, project management, and general astronomy. Its publication is timely as it should serve to remind those who guide our scientific destiny that big science projects can pay back big dividends. In the case of the AAT this is fundamental knowledge about the universe. Returning to the analogy, as with cathedrals, big is beautiful too.

Martin Ward is in the Department of Nuclear and Astrophysics, Oxford University, Particle and Nuclear Physics Laboratory, Keble Road, Oxford OX1 3RD, UK 